\title{
The effects of aerobic, resistance, and combination training on insulin sensitivity and secretion in overweight adults from STRRIDE AT/RT: a
} randomized trial

\author{
Hiba AbouAssi, ${ }^{1}$ Cris A. Slentz, ${ }^{2}$ Catherine R. Mikus, ${ }^{2}$ Charles J. Tanner, ${ }^{5}$ Lori A. Bateman, ${ }^{2}$ \\ Leslie H. Willis, ${ }^{2}$ A. Tamlyn Shields, ${ }^{5}$ Lucy W. Piner, ${ }^{2}$ Lorrie E. Penry, ${ }^{2}$ Erik A. Kraus, ${ }^{2}$ \\ Kim M. Huffman, ${ }^{6}$ Connie W. Bales, ${ }^{4}$ Joseph A. Houmard, ${ }^{5}$ and William E. Kraus ${ }^{2,3}$ \\ ${ }^{1}$ Department of Endocrinology, Duke University Medical Center, Durham, North Carolina; ${ }^{2}$ Duke Molecular Physiology \\ Institute, Duke University Medical Center, Durham, North Carolina; ${ }^{3}$ Duke Center for Living, Duke University Medical \\ Center, Durham, North Carolina; ${ }^{4}$ Division of Geriatrics, Duke University Medical Center, Durham, North Carolina; \\ ${ }^{5}$ Department of Exercise and Sports Science and Human Performance Laboratory, East Carolina University, Greenville, \\ North Carolina; and ${ }^{6}$ Physical Medicine and Rehabilitation, Veterans Affairs Medical Center, Durham, North Carolina
}

\begin{abstract}
AbouAssi H, Slentz CA, Mikus CR, Tanner CJ, Bateman LA, Willis LH, Shields AT, Piner LW, Penry LE, Kraus EA, Huffman KM, Bales CW, Houmard JA, Kraus WE. The effects of aerobic, resistance, and combination training on insulin sensitivity and secretion in overweight adults from STRRIDE AT/RT: a randomized trial. J Appl Physiol 118: 1474-1482, 2015. First published April 16, 2015; doi:10.1152/japplphysiol.00509.2014.-Most health organizations recommend a combination of aerobic training (AT) and resistance training (RT), yet few studies have compared their acute (within $24 \mathrm{~h}$ of the last exercise bout) and sustained (after 14 days of no exercise training) effects alone and in combination on glucose metabolism. The present study (Studies Targeting Risk Reduction Interventions through Defined Exercise-Aerobic Training and/or Resistance Training) compared the effects of AT, RT, and the combination (AT/RT) on insulin action at both acute and sustained phases. Subjects $(N=$ 196) were $18-70 \mathrm{yr}$ old (mean age $=50 \mathrm{yr}$ ), overweight (mean body mass index $=30 \mathrm{~kg} / \mathrm{m}^{2}$ ), sedentary with moderate dyslipidemia, and were randomized into one of three 8-mo exercise groups: 1) RT: 3 days/wk, 8 exercises, 3 sets/exercise, $8-12$ repetitions/set; 2) AT: equivalent to $\sim 19.2 \mathrm{~km} / \mathrm{wk}$ (12 miles/wk) at $75 \%$ peak $\mathrm{O}_{2}$ consumption; 3) AT/RT: the combination of AT and RT. One hundred forty-four subjects completed the intervention. Eighty-eight subjects completed all pre- and postintervention testing visits. Insulin sensitivity, glucose effectiveness, and disposition index were measured via a frequently sampled intravenous glucose tolerance test with subsequent minimal model analyses. AT/RT resulted in greater improvements in insulin sensitivity, $\beta$-cell function (disposition index), and glucose effectiveness than either AT or RT alone (all $P<0.05$ ). Approximately $52 \%$ of the improvement in insulin sensitivity by AT/RT was retained 14 days after the last exercise training bout. Neither AT or RT led to acute or chronic improvement in sensitivity index. In summary, only AT/RT (which required twice as much time as either alone) led to significant acute and sustained benefits in insulin sensitivity.
\end{abstract}

exercise intervention; IVGTT; insulin sensitivity; aerobic exercise; resistance exercise

WHILE THE BENEFITS OF BEING physically active are clear, the optimal exercise mode, amount, and intensity for specific, acute, and sustained health benefits are poorly understood.

Address for reprint requests and other correspondence: C. A. Slentz, Division of Cardiology, Dept. of Medicine, Duke Univ. Medical Center, P.O. Box 3022, Durham, North Carolina 27710 (e-mail: cris.slentz@ duke.edu).
Many organizations recommend both aerobic training (AT) and resistance training (RT) for adults $(11,12,26)$. However, these recommendations are based on the evaluation of each modality separately, as few studies have investigated the acute $(6,8,27)$ and more chronic effects of combined AT and RT (AT/RT) regimens compared with each modality. Understanding the effects of AT and RT is of critical importance if we are to apply evidence-based approaches to exercise recommendations.

STRRIDE-AT/RT (Studies Targeting Risk Reduction Interventions through Defined Exercise-Aerobic Training and/or Resistance Training) was designed to address three major questions relating to exercise recommendations for overweight, sedentary adults. First, what are the specific benefits of RT in this population? Second, how do these benefits compare with those that accrue when a similar amount of time is spent in AT? Third, are there additive, synergistic, or possibly antagonistic effects when both AT and RT are combined (AT/RT)? Answers to these questions should improve the ability of clinicians, exercise professionals, and the lay public to more accurately understand the benefits of different exercise regimens and more efficiently utilize precious exercise time. Here we summarize the effects of AT, RT, and AT/RT on insulin sensitivity ( $\mathrm{Si}$ ) as measured by the frequently sampled intravenous glucose tolerance test (IVGTT). Both the acute (within $24 \mathrm{~h}$ of last exercise bout) and sustained (after 14 days of detraining) effects on $\mathrm{Si}$ were determined.

No other studies, to our knowledge, have looked at the effects of AT, RT, and the combination of AT/RT on IVGTTderived $\mathrm{Si}$ and insulin secretion. In addition, no other studies have looked at these interventions on both acute (16-24 h after the last training bout) and more sustained (measured after 14 days without exercise) effects on $\mathrm{Si}$ and insulin secretion. Based on the consistent findings of improved $\mathrm{Si}$ with aerobic exercise, with consistent, but less data on RT $(13-15,21)$, we hypothesize that AT only and RT only will both improve $\mathrm{Si}$, and that, when added together, the effects will be additive, as opposed to synergistic or antagonistic. Furthermore, based on the findings of Houmard et al. (16), which showed that insulin action declined more dramatically in the endurance athletes, with almost no change in resistance trained athletes after 14 days without exercise, we hypothesize that RT will result in a great retention of the improvement in $\mathrm{Si}$, after 14 days without 
exercise, and that this effect will be evident in both the RT-only and AT/RT groups.

\section{METHODS}

Subjects (screening, inclusion, and exclusion criteria). Subjects recruited for the STRRIDE-AT/RT study were used in this analysis. The protocol was approved by the institutional review boards at Duke University and East Carolina University. Subjects $(n=3,145)$ responded to local advertisements and were screened by phone. Of these, 234 met inclusion criteria and were recruited into the study. Inclusion criteria were as follows: age $18-70 \mathrm{yr}$, sedentary (dedicated leisure time physical activity less than two times per week), body mass index (BMI) $26-35 \mathrm{~kg} / \mathrm{m}^{2}$, and mild to moderate dyslipidemia (LDL cholesterol 130-190 mg/dl; and/or HDL cholesterol $\leq 40 \mathrm{mg} / \mathrm{dl}$ for men or $\leq 45 \mathrm{mg} / \mathrm{dl}$ for women). Subjects were nonsmokers without a history of diabetes, hypertension, or coronary artery disease. Use of statin drugs was an exclusion criteria. After informed, written consent, subjects were asked to maintain their current lifestyle during a 4-mo run-in period, followed by randomization into one of three exercise training groups. The purpose of the run-in period was to discourage individuals who were not serious about the study commitment and thus reduce the dropout rate that may occur after randomization. Of the 234 recruited, 38 subjects dropped out during the run-in period, leaving 196 subjects for randomization. Of the subjects who were randomized, $73.5 \%(n=144)$ completed the study. Eighty-eight subjects of these had complete IVGTT data.

Insulin action measures. Insulin action was determined with a $3-\mathrm{h}$ IVGTT (4). Glucose (50\%) was injected at time zero, through an intravenous catheter placed in the antecubital space at $0.3 \mathrm{~g} / \mathrm{kg}$ body mass, and insulin $(0.025 \mathrm{U} / \mathrm{kg}$ body mass $)$ was injected at minute 20 . Twenty-nine blood samples (at minutes $0,2,3,4,5,6,8,10,12,14$, $16,19,22,23,24,25,27,30,40,50,60,70,80,90,100,120,140$, $160,180)$ were obtained, centrifuged, and stored at $-80^{\circ} \mathrm{C}$. Insulin was measured by immunoassay (Access Immunoassay System, Beckman Coulter, Fullerton, CA), and glucose with an oxidation reaction (YSI 2300, Yellow Springs, OH). Si index, glucose effectiveness (Sg; the ability of glucose to cause its own uptake into the cell at basal insulin levels), acute insulin response to intravenous glucose (AIRg; calculated as area under the insulin curve during the first $10 \mathrm{~min}$; is a measure of insulin secretion), and disposition index $(\mathrm{DI}=\mathrm{AIRg} \times \mathrm{Si}$; is considered a measure of $\beta$-cell function) were calculated using Bergman's minimal model (4). The IVGTT was performed after an overnight fast at baseline at the end of exercise training (16-24 $\mathrm{h}$ after the last exercise bout) and also 14 days after the cessation of exercise training.

Body composition. At Duke, body composition was determined using the BOD POD air displacement plethysmography method (Life Measurement, Concord, CA) on all subjects at all time points. At East Carolina University, body composition was measured by dual-energy X-ray absorptiometry machine (DEXA). As previously reported, measurements with BOD POD and DEXA are highly correlated (0.94) with one another (2). Furthermore, the focus of this analysis was on pre- to postintervention change scores; thus any differences between the study sites due to the techniques used to assess body composition did not affect the data interpretation.

Computed tomography, waist circumference, cardiopulmonary exercise testing, and strength evaluations. Body mass was measured in light clothing without shoes to the nearest $0.1 \mathrm{~kg}$ on a digital scale. The average of three weights taken over $2 \mathrm{wk}$, on different days, was used for each time point. Height was measured once, to the nearest 0.5 $\mathrm{cm}$. Computed tomography (CT) data included here have been presented previously (30). They are included in this paper again as they were used in multivariate analyses and because they are variables of interest with regard to $\mathrm{Si}$. CT scans were performed by a radiological technologist who was blinded to the subject's group assignment. With subjects in the supine position, a single, $10-\mathrm{mm}$ axial image was taken of the abdomen at the level of the $\mathrm{L}_{4}$ pedicle. A second, single 10-mm axial image was taken at the best visual location of the liver (determined by a scout image frontal radiograph taken before the liver scan). A midthigh scan (taken midway between the mid-acetabulum and the superior border of the patella) was used to determine the surface area for the thigh muscles and for adipose tissue areas. The CT images were analyzed using OsiriX imaging software, an advanced open-source PACS workstation DICOM viewer (OsiriX Foundation, Geneva, Switzerland), to determine the area of the visceral, subcutaneous, and total abdominal adipose tissue in the obtained images. With this program, once the parameters are set (e.g., definition of adipose tissue density range was set at -30 to -190 Hounsfield units), the program is largely automated. Test-retest reliability correlations for surface areas obtained are generally between $r=0.98$ and 0.99 , as the methodology is extremely reproducible. To obtain liver density, in the liver image, three $3.0-\mathrm{cm}^{2}$ circular regions of interest were manually selected, avoiding visible vessels, bile ducts, bordering surfaces, and motion artifact, and averaged to estimate liver density. One hundred and seventeen subjects had two CT tests done before the beginning of the exercise interventions, and the test retest correlation for liver density values was $0.910(P<0.0001)$ with no significant difference between test and retest means $(P=0.79)$.

Waist circumference was measured at the minimal waist (the lowest circumference measurement above the umbilicus and below the xiphoid). Minimal waist was used as our laboratory previously showed that it was more highly correlated with metabolic health than umbilical waist measures (34).

A maximal exercise test with a 12-lead ECG and expired gas analysis were performed on a treadmill using a TrueMax 2400 Metabolic Cart (ParvoMedics, Sandy, UT) before and after the exercise interventions, as described previously (10).

In RT and AT/RT subjects, the total amount of weight lifted during a single RT session was recorded each week, either by a supervising personal trainer at the East Carolina University site or electronically by the FitLinxx Strength Training Partner system (FitLinxx, Norwalk, CT) at the Duke site. The total amount of weight lifted in pounds from a typical single session during week 5 or 6 was used as the baseline measure of overall strength, and the total from a typical, single session at the end of training was used as the end of training measure of overall strength.

Exercise training (protocols, ramp period, duration, modes, verification, and adherence). The exercise groups were as follows: 1) RT (3 days/wk, 3 sets/day, 8-12 repetitions/set, 8 exercises); 2) AT [equivalent to roughly $19.2 \mathrm{~km} / \mathrm{wk}(\sim 12 \mathrm{miles} / \mathrm{wk})$ at $75 \%$ peak $\mathrm{O}_{2}$ consumption $\left(\dot{\mathrm{V}}_{2}\right)$ ]; and 3) AT plus RT (AT/RT) i.e., the full AT plus the full RT regimens.

A ramp period of $8-10 \mathrm{wk}$, designed to gradually increase the amount of aerobic exercise over time, was prescribed to all subjects in the AT and AT/RT groups. Details about the prescribed and actual exercise training amounts, intensity, and frequency are provided in Table 1. The aerobic exercise modes included treadmill, elliptical trainers, cycle ergometers, or any combination of these. As the intensity of the AT program was based on and maintained by using heart rate zones, subjects in the AT/RT group performed the AT exercise first, followed by the RT program. For aerobic exercise amount, the total number of minutes that needed to be obtained was determined by fitness level, as all subjects were prescribed a specific amount of exercise per unit body weight (i.e., $14 \mathrm{kcal} \cdot \mathrm{kg}$ body $\left.\mathrm{w}^{-1} \cdot \mathrm{wk}^{-1}\right)$. Higher fit individuals required less time to expend the prescribed number of calories per week. Exercise frequency was not prescribed; however, subjects were encouraged not to exceed 60 $\mathrm{min} /$ day. For example, a 100-kg person would be prescribed to expend $1,400 \mathrm{kcal} / \mathrm{wk}(100 \times 14)$. If their maximal $\dot{\mathrm{V}}_{\mathrm{O}_{2}}$ was $4 \mathrm{l} / \mathrm{min}$ and they exercise at $75 \%$ of that value, they consumed 3 liters oxygen per minute. Consuming 1 liter of oxygen requires $\sim 5 \mathrm{kcal}$ of energy expenditure (35). So exercise at a rate that requires 3 liters of $\dot{\mathrm{V}}_{2}$ per minute is equivalent to expending $15 \mathrm{kcal} / \mathrm{min}$. Therefore, this $100-\mathrm{kg}$ 
Table 1. Baseline demographics and exercise prescription

\begin{tabular}{|c|c|c|c|}
\hline Variables & $\begin{array}{l}\text { Resistance } \\
\text { Training }\end{array}$ & $\begin{array}{l}\text { Aerobic } \\
\text { Training }\end{array}$ & $\begin{array}{c}\text { Aerobic }+ \text { Resistance } \\
\text { Training }\end{array}$ \\
\hline$n$ & 38 & 27 & 23 \\
\hline Age, yr & $51.1(11)$ & $51.4(10)$ & $46.9(11)$ \\
\hline Body mass index, $\mathrm{kg} / \mathrm{m}^{2}$ & $30.0(3.0)$ & $30.5(3.0)$ & $30.6(3.6)$ \\
\hline \multicolumn{4}{|l|}{ Race, no. } \\
\hline Caucasian & 34 & 24 & 21 \\
\hline African American & 13 & 3 & 1 \\
\hline Other & 1 & 0 & 1 \\
\hline \multicolumn{4}{|l|}{ Sex, no. } \\
\hline Female & 18 & 14 & 13 \\
\hline Male & 20 & 13 & 10 \\
\hline \multicolumn{4}{|l|}{ Resistance exercise } \\
\hline Intensity & Progressive & & Progressive \\
\hline Rx amount ${ }^{\mathrm{a}}$, sets/wk & 72 & & 72 \\
\hline Rx time, $\min / w k$ & 180 & & 180 \\
\hline Adherence, $\%$ & $83.2(14)$ & & $79.2(16)$ \\
\hline $\begin{array}{l}\text { Actual frequency, } \\
\text { sessions/wk }\end{array}$ & $2.5(0.4)$ & & $2.4(0.5)$ \\
\hline Actual amount ${ }^{\mathrm{b}}$, sets/wk & $59.9(10)$ & & $56.7(11)$ \\
\hline \multicolumn{4}{|l|}{ Aerobic exercise } \\
\hline $\begin{array}{l}\text { Intensity, \%peak } \dot{\mathrm{V}}_{2} \\
\mathrm{Rx} \text { amount }{ }^{\mathrm{c}}\end{array}$ & & $65-80$ & $65-80$ \\
\hline $\mathrm{kcal} \cdot \mathrm{kg}^{-1} \cdot \mathrm{wk}^{-1}$ & & 14 & 14 \\
\hline Rx time, $\min / w k$ & & $132(24)$ & $134(27)$ \\
\hline Adherence*, \% & & $91.9(9)$ & $79.3(18)$ \\
\hline $\begin{array}{l}\text { Actual frequency, } \\
\text { sessions/wk }\end{array}$ & & $3.2(0.5)$ & $2.9(0.7)$ \\
\hline Actual time ${ }^{\mathrm{d}}, \mathrm{min} / \mathrm{wk}$ & & $121(20)$ & $106(32)$ \\
\hline
\end{tabular}

Values are means (SD); $n$, no. of subjects. $\dot{\mathrm{V}}_{2}, \mathrm{O}_{2}$ consumption. ${ }^{\text {aPrescrip- }}$ tion $(\mathrm{Rx})$ amount $(72 \mathrm{sets} / \mathrm{wk})=3$ days/wk, 3 sets of $8-12$ repetitions, on 8 different machines. ${ }^{\mathrm{b}}$ Actual amount $\left(\right.$ sets/wk) $=\mathrm{Rx}$ amount $\times$ adherence. ${ }^{\mathrm{c}} \mathrm{Rx}$ amount $\left(14 \mathrm{kcal} \cdot \mathrm{kg}^{-1} \cdot \mathrm{wk}^{-1}\right)$ is approximately calorically equivalent to 12 miles of jogging per week. ${ }^{\mathrm{d}}$ Actual time $(\mathrm{min} / \mathrm{wk})=\mathrm{Rx}$ time $\times$ adherence. $* P$ value $=0.002$; otherwise, there was no significant difference between groups .

person who has an exercise prescription of 1,400 kcal/wk would need to exercise $93.3 \mathrm{~min} / \mathrm{wk}(1,400 \mathrm{kcal}$ per week divided by $15 \mathrm{kcal}$ expended per minute $=93.3 \mathrm{~min} / \mathrm{wk}$ ). This subject could choose to do two sessions per week of $46.7 \mathrm{~min}$ or three sessions of $31.1 \mathrm{~min}$. Subjects were encouraged to exercise at least three times per week.

For subjects randomized to RT, the ramp period began with one set during weeks $1-2$, two sets during weeks $3-4$, building up to the prescribed three sets on week 5. RT subjects were prescribed three sessions per week (on nonconsecutive days) of three sets of 8-12 repetitions on eight Cybex weight-lifting machines designed to target all major muscle groups. Throughout the training intervention, the amount of weight lifted was increased by $5 \mathrm{lbs}$. each time the participant performed 12 repetitions with proper form on all three sets on two consecutive workout sessions to ensure a progressive RT stimulus.

All aerobic exercise sessions were verified by direct supervision and/or with a heart rate monitor that provided recorded, downloadable data (Polar Electro, Woodbury, NY). Aerobic compliance was equal to the number of minutes completed within the prescribed heart rate range, divided by the number of total weekly minutes prescribed. All RT sessions were verified by direct supervision and/or the FitLinxx Strength Training Partner.

Exercise detraining. All subjects were instructed to discontinue exercise training for 14 days after their last bout of exercise. Sixteen to twenty-four hours after their last training session, an IVGTT was obtained to assess the acute responses to the last bout plus the accumulated affect of exercise training. An IVGTT was again performed after 14 days of no exercise training to determine the longer lasting (i.e., more sustained) effects of exercise training.

Statistical analyses. Data were analyzed using Statview (SAS Institute, Cary, NC). Two-tailed, paired $t$-tests were used to determine whether the post- minus preintervention change score within each group was significant. A $P$ value of $<0.05$ was considered significant. Analysis of covariance (ANCOVA), with baseline values used as the covariate, to control for baseline differences, was used to determine if there were significant differences between groups. When the ANCOVA was significant, Fisher's post hoc analysis was performed to determine differences between groups. A post hoc $P$ value $<0.05$ was considered significant. To explore possible mechanisms responsible for the observed effects, multivariable modeling was performed using linear models with backward stepwise variable selection.

\section{RESULTS}

Baseline characteristics and the exercise programs are described in Table 1. There were no differences in age, sex, BMI, or race distribution between groups. Participants in the AT group were more adherent to the aerobic regimen compared with the participants in the AT/RT group $(P=0.002)$. No other group differences in adherence were observed.

In Table 2, baseline and change scores are presented for each group, as well as the $P$ values for the two-tailed $t$-tests that indicate which within-group change scores were significant. There was a significant increase in Si posttraining in AT/RT, but not in AT or RT. The change in $\mathrm{Si}$ in AT/RT was significantly greater than the change in $\mathrm{Si}$ in $\mathrm{AT}(P=0.006)$ and in the RT group $(P=0.001)$ (Fig. 1). BMI decreased significantly in AT and AT/RT, and there was a tendency toward an increase in RT. All three training programs led to significant increase in peak $\dot{\mathrm{V}}_{2}$, although improvements in response to the AT programs were significantly higher. As expected, the RT stimulus elicited significant increases in the total weight lifted per session in RT (increased by $49.5 \%$ ) and AT/RT (43.5\%). Fat mass decreased significantly in AT and AT/RT, with no significant change in RT. Lean body mass increased significantly only in RT. Thigh muscle adipose tissue decreased significantly in all three groups, but most markedly in AT/RT. Abdominal subcutaneous adipose tissue decreased significantly in AT and AT/RT but not RT. Visceral adipose tissue (VAT) decreased significantly only in AT.

Fasting insulin concentrations decreased in the AT and AT/RT groups. HOMA-IR decreased significantly only in the AT group. The AIRg decreased significantly $24 \mathrm{~h}$ after training only in AT. There were no differences between groups for the change in AIRg. DI, a measure of pancreatic $\beta$-cell function, increased significantly only in AT/RT. However, given that $\mathrm{DI}=\mathrm{AIRg} \times \mathrm{Si}$, and AIRg was not changed significantly in $\mathrm{AT} / \mathrm{RT}$, this increase was driven primarily by the large increase in $\mathrm{Si}$.

We were very interested in determining whether people with dysglycemia respond differently to the interventions. For the AT/RT group and for the RT-only group, fasting glucose status did not make a difference. That is, the AT/RT group had a very robust improvement in Si whether the subjects had normal or impaired fasting glucose. The RT-only group also responded the same, regardless of fasting glucose status, i.e., no change in $\mathrm{Si}$ with RT intervention. However, for the AT-only exercise intervention, there was a significant correlation $(r=-0.42)$ between baseline fasting glucose and change in $\mathrm{Si}(P<0.05)$. Subjects with fasting glucose $<100 \mathrm{mg} / \mathrm{dl}$ (i.e., normal fasting glucose) experienced an improvement in $\mathrm{Si}$ (mean $\mathrm{Si}$ change was 1.1 with SD of $2.4, N=15$ ). However, the subjects with impaired fasting glucose experienced a decrease in Si with AT 
Table 2. Baseline values, changes scores, and significance of change scores

\begin{tabular}{|c|c|c|c|c|c|c|c|c|c|}
\hline Variable & \multicolumn{3}{|c|}{ Resistance Training $(n=38)$} & \multicolumn{3}{|c|}{ Aerobic Training $(n=27)$} & \multicolumn{3}{|c|}{ Aerobic + Resistance Training $(n=23)$} \\
\hline \multicolumn{10}{|l|}{ IVGTT parameters } \\
\hline AIRg, $\mathrm{mU} \cdot 1^{-1} \cdot \min ^{-1}$ & $495(322)$ & $-35(224)$ & 0.35 & $471(352)$ & $-103(186)$ & 0.005 & $510(449)$ & $-80(248)$ & 0.14 \\
\hline DI & $1,794(1204)$ & $-114(1107)$ & 0.53 & $1813(1341)$ & $-230(1047)$ & 0.26 & 1465 (1192) & $1069(1696)$ & 0.006 \\
\hline $\mathrm{Sg}$, per min & $0.0243(0.011)$ & $-0.001(0.016)$ & 0.82 & $0.0231(0.014)$ & $-0.001(0.014)$ & 0.81 & $0.0208(0.012)$ & $0.007(0.014)$ & 0.031 \\
\hline HOMA & $2.15(1.12)$ & $0.05(1.3)$ & 0.83 & $2.43(1.72)$ & $-0.59(0.9)$ & 0.002 & $2.21(1.15)$ & $-0.24(1.16)$ & 0.33 \\
\hline Weight, kg & $88.8(16.0)$ & $0.81(2.4)$ & 0.049 & $88.8(11.5)$ & $-1.63(3.2)$ & 0.013 & $91.7(11.4)$ & $-1.64(3.04)$ & 0.017 \\
\hline $\mathrm{BMI}, \mathrm{kg} / \mathrm{m}^{2}$ & $30.0(3.0)$ & $0.24(0.8)$ & 0.08 & $30.5(3.0)$ & $-0.63(1.2)$ & 0.008 & $30.6(3.6)$ & $-0.48(1.1)$ & 0.04 \\
\hline Waist circumference, $\mathrm{cm}$ & $96.5(9.6)$ & $0.15(1.7)$ & 0.59 & $97.1(11.0)$ & $-0.85(2.6)$ & 0.10 & $98.0(9.9)$ & $-1.98(2.8)$ & 0.002 \\
\hline \multicolumn{10}{|l|}{ Peak $\dot{\mathrm{V}}_{2}$} \\
\hline $\mathrm{ml} \cdot \mathrm{kg}^{-1} \cdot \mathrm{min}^{-1}$ & $27.3(6.1)$ & $1.40(2.9)$ & 0.005 & $27.1(5.6)$ & $3.91(2.6)$ & $<0.0001$ & $27.4(5.8)$ & $4.13(3.2)$ & $<\mathbf{0 . 0 0 0 1}$ \\
\hline Strength, $\mathrm{kg} / \mathrm{session}$ & $20,130(8,031)$ & $9,956(5,798)$ & $<0.0001$ & NA & NA & NA & $20,411(5,383)$ & $8,887(6,105)$ & $<\mathbf{0 . 0 0 0 1}$ \\
\hline Liver fat, HU & $58.3(8.3)$ & $0.70(5.1)$ & 0.46 & $57.4(9.8)$ & $2.05(5.9)$ & 0.09 & $56.5(14.2)$ & $0.66(5.8)$ & 0.60 \\
\hline
\end{tabular}

Values are means (SD); $n$, no. of subjects. There were no significant baseline differences between groups. IVGTT, intravenous glucose tolerance tests with minimal model analyses; $\mathrm{Si}$, insulin sensitivity index from IVGTT; AIRg, acute insulin response to infused glucose (area under the curve during first 10 min); DI, disposition index, a measure of pancreatic beta cell function $=\mathrm{Si} \times$ AIRg (there are no units for this measure); AT, adipose tissue; $\mathrm{Sg}$, glucose effectiveness, ability of glucose to cause its own uptake into cells; SAT, subcutaneous adipose tissue. Liver fat is estimated from liver density with Housfield Units (HU). Note: Only the IVGTT variables presented here are new and have not been published previously, and they are the focus of this paper. The additional data provided are helpful for interpreting the IVGTT data within the context of the other variables presented. $P$ values in bold are significantly different.

exercise (mean Si change was -0.92 with $\mathrm{SD}$ of $3.0, N=12$ ). Albeit the subjects' numbers were small, the difference in the changes in Si between subjects with normal fasting glucose and impaired fasting glucose trended toward significance $(P<$ $0.08)$. Interestingly, the detraining responses were similar. That is, no difference based on fasting glucose status for RT and AT/RT groups, but a trend $(P<0.061)$ toward a significant difference between subjects with normal glucose and impaired fasting glucose after 14 days of no exercise.
We were very interested in this finding and, fortunately, we had nearly identical data from our laboratory's first STRRIDE study (17), so we went back and looked at those data. We had an identical exercise group (AT only, with same intensity and same amount of exercise) with nearly identical subject population (mild to moderate dyslipidemia, same as in the present study) and with complete IVGTT data. However, in this study, we saw no effect of glucose status on the change in $\mathrm{Si}$ (impaired fasting glucose subjects, $N=12$, Si change was 0.84
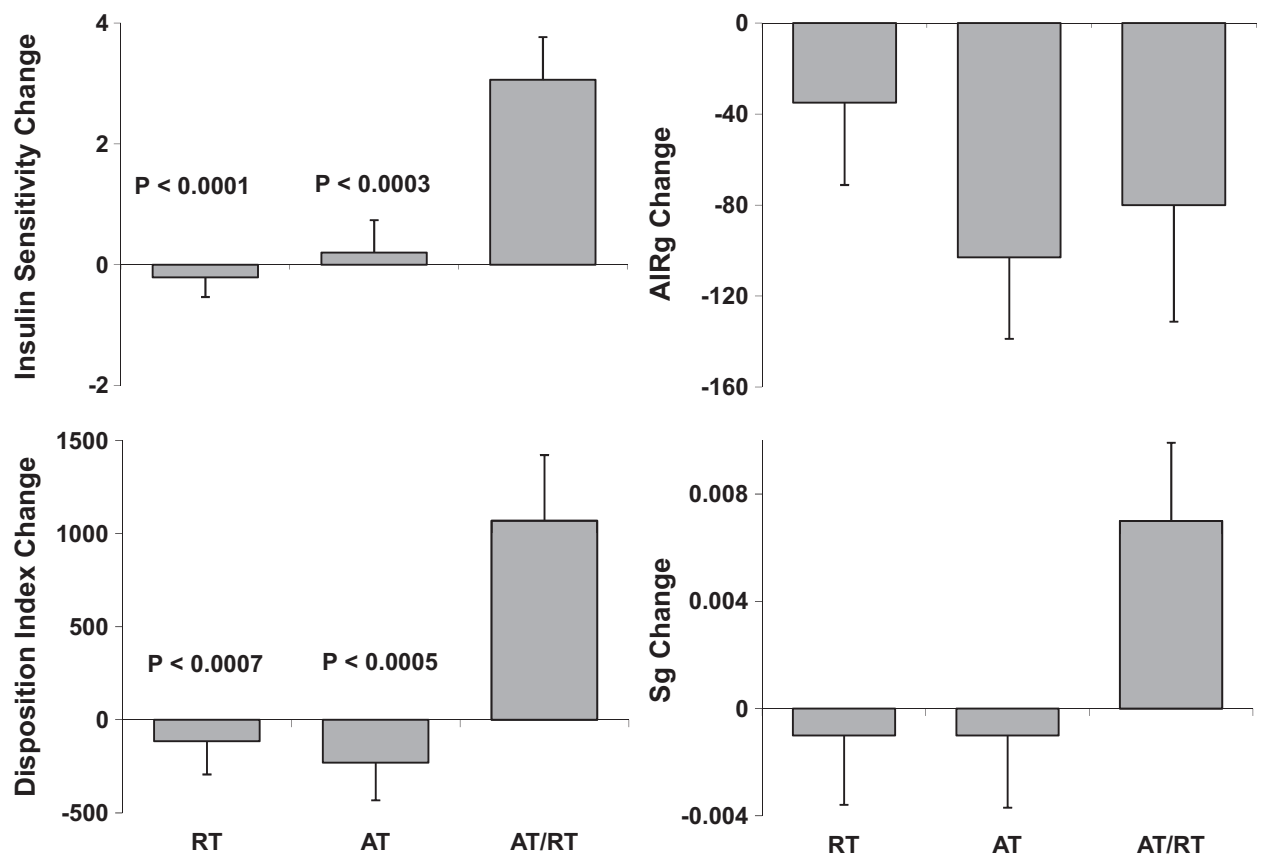

Fig. 1. The values are post- minus pretraining (means $\pm \mathrm{SE}$ ). These parameters are all derived from the intravenous glucose tolerance test (IVGTT) with minimal model analyses. Top left: insulin sensitivity ( $\mathrm{Si}$; units are $\left.\mathrm{mU} \cdot 1^{-1} \cdot \mathrm{min}^{-1}\right)$. Top right: acute insulin response to glucose infusion (AIRg; units are $\left.\mathrm{mU} \cdot 1^{-1} \cdot \mathrm{min}^{-1}\right)=$ area under the insulin curve during first $10 \mathrm{~min}$ of test. Bottom right: glucose effectiveness $(\mathrm{Sg}$; units are per minute), which is defined as the ability of glucose to cause its own uptake. Bottom left: disposition index (DI; no units for this term as the units for $\mathrm{Si}$ and AIRg cancel each other out $)=\operatorname{AIRg} \times \mathrm{Si}$ and is considered a measure of $\beta$-cell function. All $P$ values refer to significant differences between the group indicated [aerobic training (AT) or resistance training (RT)] vs. the combination AT/RT based on post hoc tests for significant difference between groups. That is, AT/RT was significantly different from both AT and RT for $\mathrm{Si}, \mathrm{Sg}$, and DI. 


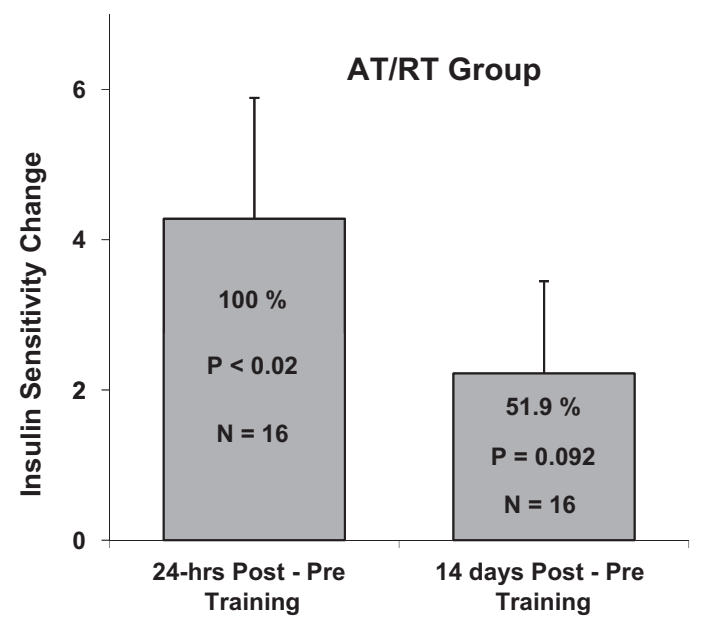

Fig. 2. Retention of the improvement in $\mathrm{Si} 14$ days after the last exercise training bout. Of the 23 subjects in AT/RT with Si measured before training and 24-h after the last training bout, only 16 of these subjects also had IVGTT data at the 14-day detraining time point. To determine the percentage of the improvement in $\mathrm{Si}$ that was sustained after 14 days of no exercise, we used only subjects who had IVGTT data at all three time points. Just over one-half of the effect was sustained after 14 days. This amount trended toward significance $(P=0.092)$. The other two groups (AT and RT) did not have a significant improvement in $\mathrm{Si}$ at $24 \mathrm{~h}$, and there was no change at 14 days. Values are means $\pm \mathrm{SE} ; N$, no. of subjects.

with SD of 1.6; and in normal fasting glucose subjects, $N=38$, Si change was 0.88 with SD of 1.9).

Detraining/sustained effects. A little over one-half (52\%) of the acute improvement in $\mathrm{Si}$ observed $24 \mathrm{~h}$ after the last training bout in the AT/RT group persisted after 14 days of detraining (see Fig. 2, see also Table 3). As a result, it would appear that one-half of the overall total training effect measured at $24 \mathrm{~h}$ after the last exercise bout was acute and one-half was sustained/chronic. However, it is important to point out that positive change in $\mathrm{Si}$ only trended toward significance after 14 days of no exercise $(P=0.056$; Table 3$)$. Although with fewer subjects $(N=15$ for AT/RT detraining data, compared with $N=23$ for 24 -h posttraining data), there is decreased power to detect a significant difference. Similarly, we see that DI showed a trend toward significant improvement after 14 days in the AT/RT group $(P=0.071$; Table 3$)$. Interestingly, there was also a trend for change in DI for the AT-only group; however, in this case, the trend was for a negative change, i.e., DI (a marker of $\beta$-cell function) trended toward a decrease below beginning baseline values.

Finally, in most, but not all cases, the variations (as indicated by the standard deviations of the changes) in the change scores for detraining changes (Table 3 ) were somewhat larger than the variation observed for change scores from Table 2, indicating a slightly larger variation in detraining responses than training responses. This would seem to indicate that the detraining effects (i.e., the rate at which the training effects deteriorate after training cessation) vary more from individual to individual than the training effects.

Multivariate analyses and possible mechanisms. To explore possible mechanisms responsible for the observed effects, multivariable modeling was performed using linear models with backward stepwise variable selection. We included variables describing change in cardiorespiratory fitness (peak $\dot{\mathrm{V}}_{2}$ ), regional adiposity [liver fat, thigh muscle adipose tissue, subcutaneous abdominal adipose tissue, VAT, waist circumference, and body composition (lean body mass, fat mass, BMI)]. None of these variables explained the acute effect of AT/RT on $\mathrm{Si}$, although change in VAT approached statistical significance $(P=0.07)$. With detraining, the final regression model included VAT, fat mass, and lean body mass as significant predictors of change in $\mathrm{Si}\left(R^{2}=0.32, P=0.007\right)$.

Outlier analyses. For the key variable of Si from the IVGTT test, we removed three subjects who had very high baseline measures, as they were $>3$ SDs from the mean. We also removed one subject who had a change in $\mathrm{Si}$ with training which was $>4$ SD from the mean. Removing these outliers had no appreciable effect on the overall findings or interpretation with regard to statistical significance. Leaving the outliers in had large effects on the means and SDs of Si and change in Si. Therefore, we removed these outliers.

In Fig. 3, we show the raw glucose and insulin data obtained from the 180-min IVGTT (in addition to the major outcome variables obtained through minimal model analyses shown in earlier tables and figures). The three graphs in Fig. 3, left, are of the glucose values during the IVGTT for the AT, RT, and AT/RT groups. The three graphs in Fig. 3, right, are of the insulin values during the IVGTT for these groups. Insets for each graph show expanded views for the 19- through 80-min time periods and emphasize the larger decrease in glucose values (for the graph insets on the left) for the postexercise training vs. pretraining curves, over this time period, observed in the AT/RT group compared with AT- and RT-only groups. The insets on the right (insulin graphs) show virtually no prevs. posttraining difference in insulin responses for the AT- and RT-only groups compared with a noticeable reduction in the insulin curve observed after training vs. before training in the AT/RT group. These data support the minimal model results, which showed robust improvement in Si for the AT/RT group,

Table 3. Baseline frequently sampled IVGTT values plus 14-day detraining changes scores with significance of detraining change scores

\begin{tabular}{|c|c|c|c|c|c|c|c|c|c|}
\hline Variable & \multicolumn{3}{|c|}{ Resistance Training $(n=27)$} & \multicolumn{3}{|c|}{ Aerobic Training $(n=21)$} & \multicolumn{3}{|c|}{ Aerobic + Resistance Training $(n=16)$} \\
\hline $\mathrm{Si}, \mathrm{mU} \cdot 1^{-1} \cdot \min ^{-1}$ & $4.30(1.8)$ & $-0.55(2.5)$ & 0.27 & $4.94(3.3)$ & $0.58(3.6)$ & 0.47 & $3.91(3.1)$ & $2.22(4.9)$ & 0.056 \\
\hline DI & $2,114(1,237)$ & $-318(1,428)$ & 0.26 & $1,943(1,459)$ & $-548(1,313)$ & 0.071 & $1,527(935)$ & $805(1,983)$ & 0.13 \\
\hline $\mathrm{Sg}$, per min & $0.024(0.011)$ & $0.002(0.015)$ & 0.59 & $0.025(0.013)$ & $-0.006(0.015)$ & 0.077 & $0.021(0.008)$ & $0.005(0.019)$ & 0.33 \\
\hline
\end{tabular}

Values are means (SD); $n$, no. of subjects. There were no significant baseline differences between groups. Frequently sampled ( 29 blood samples over 180 min) IVGTT was used. Note: the values per group in this table include only subjects who have both baseline and detraining data and, therefore, are a different/lower number than those from Table 2, who have baseline and end-of-exercise data only. 

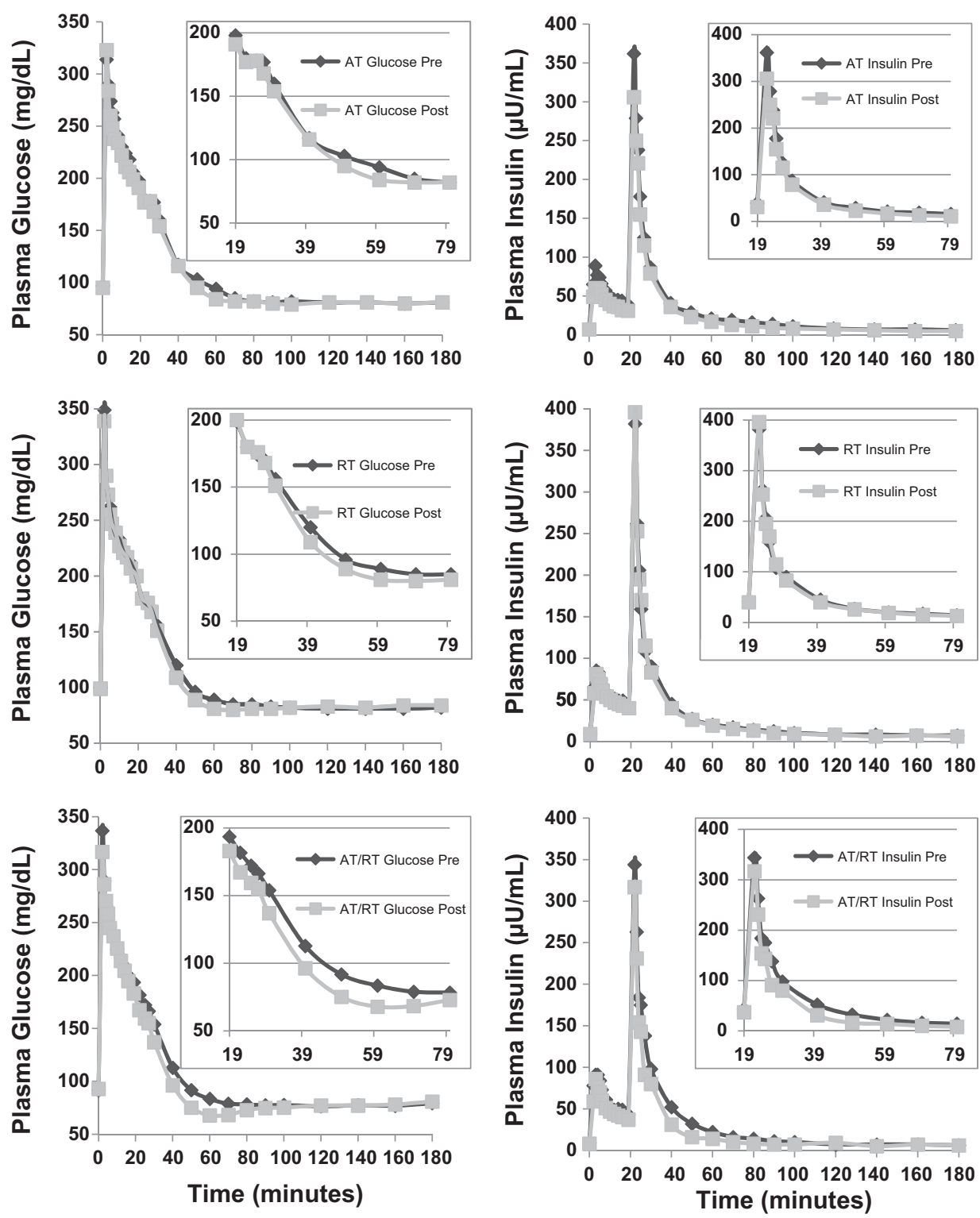

Fig. 3. IVGTT raw data figures for each group for glucose values and insulin values over the $180 \mathrm{~min}$ of the IVGTT. Left: the three graphs are of the glucose values during the IVGTT for the AT (top), RT (middle), and AT/RT (bottom) groups. Right: the three graphs are of the insulin values during the IVGTT for the AT (top), RT (middle), and AT/RT (bottom) groups. Insets for each graph show expanded views for the 19-min (just before the insulin infusion at $20 \mathrm{~min}$ ) through 80 -min time periods. These insets emphasize the much larger decrease in glucose values (for the graph insets on the left) for the postexercise training vs. pretraining curves, over this time period, observed in the AT/RT group compared with AT and RT only groups. The insets on the right (insulin graphs) show virtually no difference in insulin responses for the AT- and RT-only groups compared with a noticeable reduction in the insulin curve observed after training vs. before training in the AT/RT group. Values are means $\pm \mathrm{SE}$. compared with no significant difference in pre- vs. posttraining data for either the AT- or the RT-only groups.

\section{DISCUSSION}

Determining how much exercise, what intensities, and what types of exercise (modes) are most beneficial for acquiring specific health benefits, realizing that not any one amount or type of exercise is likely to be best for every health benefit, is of great interest to public health $(10,17,18,20,22,31,32)$. Determining the effects of these different exercise programs on their ability to sustain health benefits when exercise is interrupted (i.e., during brief periods of detraining) can provide important information as to durability and provide insights as to the possible biological mechanisms underlying traininginduced improvements in health parameters $(1,22,31,33)$. That is, both the magnitude of the health benefit of regular exercise and the ability to sustain the health benefit are important factors in determining optimal exercise prescriptions for specific health benefits. To our knowledge, this is the first randomized trial to directly compare the acute and sustained effects induced by comparable amounts of time spent doing $\mathrm{RT}$, or AT, and the combination of the RT/AT programs on insulin action in overweight/obese middle- to older-aged adults.

There were three major findings from the present study. First, the combination of $8 \mathrm{mo}$ of RT/AT (which required approximately twice as much exercise training time as either alone) resulted in significantly greater improvements in Si than did either AT or RT alone (Fig. 1). Second, the combination of AT/RT also resulted in significantly larger improvements in the DI (a measure of $\beta$-cell function; DI $=\mathrm{Si} \times \mathrm{AIRg}$ ) and $\mathrm{Sg}$ (a measure of how well glucose can cause its own cellular uptake) than did either AT or RT (Fig. 1). Neither AT or RT resulted in improvements in $\mathrm{Si}$, DI, or $\mathrm{Sg}$. All three exercise programs resulted in reduced $\mathrm{AIRg}$, and, while this reduction was only significant in AT, there was no significant difference in change scores among the groups. Third, in addition to the robust improvement in $\mathrm{Si}$ observed in AT/RT $24 \mathrm{~h}$ after the last 
training bout, $\sim 52 \%$ of this improvement in $\mathrm{Si}$ was retained up to 14 days after the last bout of exercise (Fig. 2), an effect that appears to be associated with changes in body composition. This is not surprising, as our laboratory has previously shown that fat, particularly visceral fat, is significantly correlated to variables of metabolic risk $(29,34)$. The acute improvements in $\mathrm{DI}$ and $\mathrm{Sg}$ were not sustained over the more prolonged detraining period. Importantly, the participants in AT/RT exercised for approximately double the time of the participants in either RT or AT. Thus, while it is tempting to suggest that the synergistic effect was due to combining the two different modes of exercise, we cannot rule out the possibility that the effect was due to a greater total amount of exercise.

The finding that effects of combined AT/RT were superior to either AT or RT alone is consistent with previous reports on glucose control $(\mathrm{HbA} 1 \mathrm{c})$ in patients with type 2 diabetes $(6$, 27) and physical function in nondiabetic humans (8). This is particularly true when the AT/RT group is the additive combination of the AT and RT programs, as was the case in the present study and in prior work by Sigal et al. (27). By comparison, both Church et al. (6) and Davidson et al. (8) controlled for total time, such that the AT group and the AT/RT groups had approximately equal training times each week. While Church et al. did not observe their AT/RT to be significantly better than their AT group in reducing $\mathrm{HbA1c}$, only AT/RT was significantly better than control. Interestingly, both the AT and the AT/RT groups were similarly effective when comparing the effects for the subgroup of diabetic humans with elevated baseline $\mathrm{HbA1c}$ values $\geq 7.0 \%$. In contrast, while Davidison et al. observed that AT/RT was significantly better than AT for improving measures of physical function in nondiabetic humans, improvements in insulin action determined with hyperinsulinemic-euglycemic clamps were not different between AT and AT/RT groups. Thus, in general, when the amount of exercise training exposure time is equal, there do not appear to be large differences among AT/RT and AT. However, when the total time for AT/RT is the linear combination of the AT and RT, i.e., twice as much time, the differences are more robust.

It was surprising that neither AT or RT improved $\mathrm{Si}$, while the combination of the two had a very robust effect. Exercise training is consistently reported to improve $\mathrm{Si}(13-15,21)$ (reviews are cited for brevity), especially when insulin action is measured within $24-48 \mathrm{~h}$ after the last training bout. The strong training stimuli of $\mathrm{AT}$ and $\mathrm{RT}$ are reflected in robust improvements in peak $\dot{\mathrm{V}}_{2}$ for $\mathrm{AT}$, and improvements in strength and lean body mass for RT. One difference between our study and most studies that have found increased Si with AT and/or RT is that most other studies measured Si with either an oral glucose tolerance test (OGTT) or the hyperinsulinemic-euglycemic clamp. It is possible that these more straightforward methods are more sensitive to exercise effects. Although the IVGTT, OGTT, and clamp are all validated techniques for assessing $\mathrm{Si}$, methodological differences may at least partially explain discordance between our study and others. Specifically, neither the clamp or the OGTT require complex mathematical modeling. On the other hand, the raw results from an IVGTT must undergo minimal model analyses, a model that is based on a great deal of research and numerous complex assumptions. Importantly, we have previously observed and reported significant improvements in Si measured via IVGTT in response to the same AT stimulus employed in the present study (17). However, it should be noted that baseline $\mathrm{Si}$ was lower in the previous study (3.4 vs. 4.5 $\mathrm{mU} \cdot \mathrm{l}^{-1} \cdot \mathrm{min}^{-1}$ in the present study), indicating that the relatively high baseline $\mathrm{Si}$ in the present study may explain, at least in part, why no statistically significant improvements in $\mathrm{Si}$ were observed in the present study. It is also important to point out that, of the three different exercise training interventions tested in STRRIDE (17), the intervention used in the present study showed the smallest improvement of the three.

IVGTT derived measures of $\mathrm{Si}$ are considered to be reflective of muscle or peripheral $\mathrm{Si}$, while HOMA, a fasting $\mathrm{Si}$ measure, is thought to reflect hepatic Si. It is interesting, therefore, that the AT group showed improvement in HOMA and fasting insulin, but not Si (IVGTT-derived Si measure), which would suggest that aerobic exercise training, in this population, improved hepatic, but not muscle $\mathrm{Si}$. That both visceral fat and liver fat were also reduced in this group adds support to the idea that hepatic Si was improved. Furthermore, that the AT-only and the AT/RT groups did not have a significant reductions in HOMA and also did not experience significant reductions in visceral and/or liver fat is consistent with this hypothesis, i.e., that visceral and liver fat changes are associated with changes in hepatic Si.

That said, the minimal effects of AT or RT and the robust effects of AT/RT on Si in the present study were quite similar to the independent results our laboratory obtained for metabolic syndrome (3), which is, conceptually, highly related to insulin resistance (19). In our laboratory's previous report, we observed that combined AT/RT significantly improved both the ATP III metabolic syndrome score (a sum of five dichotomous scores from fasting glucose, blood pressure, waist circumference, triglycerides, and HDL-cholesterol) and the more sensitive $z$-score of the metabolic syndrome measures ( $P<0.005$ for both change scores). However, AT had no effect on the ATP III metabolic syndrome score, and RT actually resulted in a borderline significant $(P=0.054)$ deterioration in this score. For the metabolic syndrome $z$-score, the RT program had no effect, and the AT program trended toward a significant improvement $(P=0.07)$. Taken together, these changes in metabolic syndrome scores are very similar to the change in $\mathrm{Si}$ and give confidence about the observed changes in Si using the IVGTT.

Another possible explanation exists. It is possible that obese subjects and/or subjects with metabolic syndrome may have a more blunted change in $\mathrm{Si}$ in response to resistance exercise training. Malin et al. (24) recently showed that nondiabetic obese women experienced blunted improvements in postprandial Si compared with lean controls after a RT program. In another study, Layne et al. (23) found that subjects with metabolic syndrome have blunted improvements in Si after RT. They attributed this to impaired muscle AMP-activated protein kinase activation. The subjects in the present study had a prevalence of metabolic syndrome of $\sim 45 \%$. These factors may explain our findings of no significant effect of RT alone or AT alone on Si.

Whether the effects of exercise training on $\mathrm{Si}$ are almost completely a result of acute effects (lasting for 24-72 h) or more sustained has not been investigated often. In the present study, we observed that $52 \%$ of the total improvement in $\mathrm{Si}$ seen $24 \mathrm{~h}$ after the last training bout in the AT/RT group was 
still evident 15 days after training had stopped. Previously, we reported that $36 \%$ of the total improvement in $\mathrm{Si}$ was still evident 30 days after the last training bout of an intense period of AT (33). More recently, in a much larger study, we observed that, with the AT exposure used in this study, there was no significant difference between $\mathrm{Si}$ measured after 15 days of detraining and baseline $\mathrm{Si}$ (1). However, with a larger exposure (by $50 \%$ ) at the same intensity, we observed that Si was still significantly greater than baseline values at 15 days of detraining $(\sim 70 \%)$, which was associated with a reduction in fat mass obtained during training (1). For the present study, the final regression model included changes in VAT, total body fat mass, and lean body mass $\left(R^{2}=0.32, P=0.007\right)$, suggesting that changes in body composition explain $32 \%$ of the chronic effect $(5,25)$.

Important strengths of this study include the following: 1) the randomized study design; 2) the inclusion of three training programs in the same study; 3) direct verification of exercise amount, intensity, and, therefore, exposure, of the AT, RT, and AT/RT interventions; 4) the inclusion of a substantial RT program that reduces the likelihood that negative findings are due to an inadequate RT stimulus; 5) a significant proportion of women and minorities in the study population; and 6) the additive nature of the combination program, permitting the assessment of additive or interacting effects of AT and RT. A limitation of this study is that the participants were motivated men and women who volunteered to exercise in a semisupervised setting, limiting generalizability of the findings to the general population. This was an efficacy study, not an intentto-treat study, which has known strengths and limitations.

Summary. The major findings here were that a linear combination of AT and RT robustly improved Si, and that approximately one-half of the beneficial effect was maintained over 14 days of detraining. When examining the results of the STRRIDE-AT/RT trial over many health-related variables, it is clear that AT/RT had the largest (albeit not always significantly larger) improvements in $\mathrm{Si}, \mathrm{DI}, \mathrm{Sg}$, body composition (reflecting both reductions in fat mass and increases in lean mass), waist circumference, blood pressure, peak $\dot{\mathrm{V}}_{2}$, and metabolic syndrome. As individuals in the AT/RT group trained for approximately twice as much time each week, we cannot determine whether greater improvements were due to qualitative synergistic effects of the two very different exercise modes, or whether the effects were due to a greater amount of exercise, or a combination of both. Previous studies that have shown only minimal differences between AT/RT and AT when total training time is equal suggest that the more robust effects observed in the present study were likely due to the greater total training time.

\section{GRANTS}

This study was conducted with study funds provided by the National Institutes of Health National Heart, Lung, and Blood Institute (2R01-HL057354), Clinical Trial Registration no. NCT00275145.

\section{DISCLOSURES}

No conflicts of interest, financial or otherwise, are declared by the author(s).

\section{AUTHOR CONTRIBUTIONS}

Author contributions: H.A., C.A.S., C.R.M., C.J.T., L.A.B., L.H.W., L.W.P., E.A.K., K.M.H., J.A.H., and W.E.K. analyzed data; H.A., C.A.S., C.R.M., C.J.T., E.A.K., K.M.H., J.A.H., and W.E.K. interpreted results of experiments; H.A. and C.A.S. prepared figures; H.A., C.A.S., and C.R.M. drafted manuscript; H.A., C.A.S., C.R.M., C.J.T., L.A.B., L.H.W., A.T.S., L.W.P., L.E.E.-P., E.A.K., K.M.H., C.W.B., J.A.H., and W.E.K. approved final version of manuscript; C.A.S., J.A.H., and W.E.K. conception and design of research; C.A.S., C.J.T., L.A.B., L.H.W., A.T.S., L.W.P., L.E.E.-P., K.M.H., C.W.B., and W.E.K. performed experiments; C.A.S., C.R.M., C.J.T., L.A.B., L.H.W., A.T.S., L.W.P., L.E.E.-P., K.M.H., C.W.B., J.A.H., and W.E.K. edited and revised manuscript.

\section{REFERENCES}

1. Bajpeyi S, Tanner C, Slentz C, Duscha B, McCartney J, Hickner R, Kraus W, Houmard J. Effect of exercise intensity and volume on persistence of insulin sensitivity during training cessation. J Appl Physiol 106: 1079-1085, 2009.

2. Ball S, Altena T. Comparison of the BodPod and DEXA in men. Physiol Meas 25: 671-678, 2004.

3. Bateman L, Slentz C, Willis L, Shields A, Piner L, Bales C, Houmard J, Kraus W. Comparison of aerobic versus resistance exercise training on metaoblic syndrome (from Studies of a Targeted Risk Reduction Intervention Through Defined Exercies-STRRIDE AT/RT). Am J Cardiol 108: 838-844, 2011.

4. Bergman R, Finegood D, Ader M. Assessment of insulin sensitivity in vivo. Endocr Rev 6: 45-86, 1985.

5. Brochu M, Starling R, Tchernof A, Matthews D, Garcia-Rubi E, Poehlman E. Visceral adipose tissue is an independent correlate of glucose disposal in older obese postmenopausal women. J Clin Endocrinol Metab 85: 2378-2384, 2000.

6. Church T, Blair S, Cocreham S, Johannsen N, Johnson W, Kramer K, Mikus C, Myers V, Nauta M, Rodarte R, Sparks L, Thompson A, Earnest C. Effects of aerobic and resistance training on HbA1c in patients with type 2 diabetes-a randomized, controlled trial. JAMA 304: 22532262, 2010.

8. Davidson LE, Hudson R, Kilpatrick K, Kuk JL, McMillan K, Janiszewski PM, Lee S, ML, Ross R. Effects of exercise modality on insulin resistance and functional limitation in older adults: a randomized controlled trial. Arch Intern Med 169: 122-131, 2009.

10. Duscha B, Slentz C, Johnson J, Houmard J, Bensimhon D, Knetgzer $\mathbf{K}$, Kraus W. Effects of exercise training amount and intensity on peak oxygen comsumption in middle-aged men and women at risk for cardiovascular disease. Chest 128: 2788-2793, 2005.

11. Fletcher GF, Ades PA, Kligfield P, Arena R, Balady GJ, Bittner VA, Coke LA, Fleg JL, Forman DE, Gerber TC, Gulati M, Madan K, Rhodes J, Thompson PD, Williams MA; American Heart Association Exercise, Cardiac Rehabilitation, and Prevention Committee of the Council on Clinical Cardiology, Council on Nutrition, Physical Activity and Metabolism, Council on Cardiovascular and Stroke Nursing, and Council on Epidemiology and Prevention. Exercise standards for testing and training: a scientific statement from the American Heart Association. Circulation 128: 873-934, 2013.

12. Garber CE, Blissmer B, Deschenes MR, Franklin BA, Lamonte MJ, Lee IM, Nieman DC, Swain DP; American College of Sports Medicine. American College of Sports Medicine position stand. Quantity and quality of exercise for developing and maintaining cardiorespiratory, musculoskeletal, and neuromotor fitness in apparently healthy adults: guidance for prescribing exercise. Med Sci Sports Exerc 43: 1334-1359, 2011.

13. Goodyear L, Kahn B. Exercise, glucose transport, and insulin sensitivity. Annu Rev Med 49: 235-261, 1998.

14. Henriksen E. Exercise effects of muscle insulin signaling and action. Invited Review: Effects of acute exercise and exercise training on insulin resistance. J Appl Physiol 93: 788-796, 2001.

15. Holloszy J, Schultz J, Kusnierkiewicz J, Hagberg J, Ehsani A. Effects of exercise on glucose tolerance and insulin resistance. Brief review and some preliminary results. Acta Med Scand Suppl 711: 55-65, 1986.

16. Houmard J, Hortobagyi T, Neufer P, Johns R, Fraser D, Isreal R, Dohm G. Training cessation does not alter muscular GLUT-4 protein levels. J Appl Physiol 74: 776-781, 1993.

17. Houmard J, Tanner C, Slentz C, Duscha B, McCartney J, Kraus W. Effect of the volume and intensity of exercise training on insulin sensitivity. J Appl Physiol 96: 101-106, 2004.

18. Johnson J, Slentz C, Houmard J, Samsa G, Duscha B, Aiken L, McCartney J, Tanner C, Kraus W. Exercise training amount and intensity effects on metabolic syndrome: STRRIDE. Am J Cardiol 100: $1759-1767,2007$. 
19. Kraemer F, Ginsberg H, Gerald M, Reaven MD. Demonstration of the central role of insulin resistance in type 2 diabetes and cardiovascular disease. Diabetes Care 37: 1178-1181, 2014.

20. Kraus W, Houmard J, Duscha B, Knetgzer K, Wharton M, McCartney J, Bales C, Henes S, Samsa G, Otvos J, Kulkarni K, Slentz C. Effects of the amount and intensity of exercise on plasma lipoproteins. $N$ Engl J Med 347: 1483-1492, 2002.

21. Kraus W, Slentz C. Metabolic syndrome: recognition, etiology and physical fitness as a component. In: Nutrition and Diabetes: Pathophysiology and Management, edited by Opara E. Boca Raton, FL: Taylor \& Francis Group, CRC Press, 2006, p. 57-78.

22. Kraus W, Torgan C, Duscha B, Norris J, Brown S, Cobb F, Bales C, Annex B, Samsa G, Houmard J, Slentz C. Studies of a targeted risk reduction intervention through defined exercise (STRRIDE). Med Sci Sports Exerc 33: 1774-1784, 2001

23. Layne A, Nasrallah S, South M, Howell M, McCurry M, Ramsey M, Stone M, Stuart C. Impaired muscle AMPK activation in the metabolic syndrome may attenuate improved insulin action after exercise training. $J$ Clin Endocrinol Metab 96: 1815-1826, 2011.

24. Malin S, Hinnerichs K, Echtenkamp B, Evetovich T, Engebretsen B. Effect of adiposity on insulin action after acute and chronic resistance exercise in non-diabetic women. Eur J Appl Physiol 113: 2933-2941, 2013.

25. Ross R, Fortier L, Hudson R. Separate associations between visceral and subcutaneous adipose tissue distribution, insulin and glucose levels in obese women. Diabetes Care 19: 1404-1411, 1996.

26. Sigal R, Kenny G, Wasserman D, Castaneda-Sceppa C, White R. Physical activity/exercise and type 2 diabetes: a consensus statement from the ADA. Diabetes Care 29: 1433-1438, 2006.
27. Sigal RJ, Kenny GP, Boule NG, Wells GA, Prud'homme D, Fortier M. Effects of aerobic training, resistance training, or both on glycemic control in type 2 diabetes: a randomized trial. Ann Intern Med 147: 357-369, 2007.

29. Slentz C, Aiken L, Houmard J, Bales C, Johnson J, Tanner C, Duscha B, Kraus W. Inactivity, exercise and visceral fat. STRRIDE: a randomized, controlled study of exercise intensity and amount. J Appl Physiol 99: 1613-1618, 2005.

30. Slentz C, Bateman L, Willis L, Shields A, Tanner C, Piner L, Hawk V, Muehlbauer M, Samsa G, Nelson R, Huffman K, Bales C, Houmard J, Kraus W. Effects of aerobic vs resistance training on visceral and liver fat stores, liver enzymes, and insulin resistance by HOMA in overweight adults from STRRIDE AT/RT. Am J Physiol Endocrinol Metab 301: E1033-E1039, 2011.

31. Slentz C, Houmard J, Johnson J, Bateman L, Tanner C, McCartney J, Duscha B, Kraus W. Inactivity, exercise training and detraining, and plasma lipoproteisn. STRRIDE: a randomized, controlled study of exercise intensity and amount. $J$ Appl Physiol 103: 432-442, 2007.

32. Slentz C, Tanner C, Bateman L, Durheim M, Huffman K, Houmard J, Kraus W. Effects of exercise training intensity on pancreatic beta cell function. Diabetes Care 32: 1807-1811, 2009.

33. Slentz C, Torgan C, Houmard J, Tanner C, Kraus W. Long-term effects of exercise training and detraining on carbohydrate metabolism in overweight subjects. Clin Exerc Physiol 4: 22-28, 2002.

34. Willis L, Slentz C, Houmard J, Johnson J, Duscha B, Aiken L, Kraus W. Minimal versus umbilical waist circumference measures as indicators of cardiovascular disease risk. Obesity (Silver Spring) 15: 753-759, 2007.

35. Zuntz N. Thermal equivalent of oxygen consumption for nonprotein respiratory quotient. Pflugers Arch 83: 557, 1901.

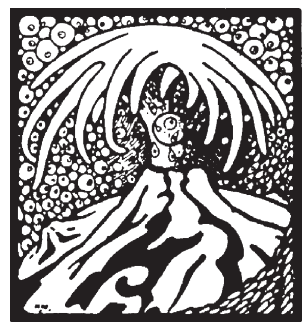

